\title{
Thoracoscopic Sympathectomy for Treatment of Primary Hyperhidrosis in Children: a Randomized Comparative Study between Clipping and Electrocautery Techniques
}

\author{
Mahmoud Abdelaziz Elshahawy ${ }^{1, *}$ MSc., Abdel Moniem Shams Eldeen ${ }^{2}$ MD. \\ and Mabrouk Maowd $\mathrm{Akl}^{2} \mathrm{PhD}$.
}

\author{
* Corresponding Author: \\ Mahmoud Abdelaziz Elshahawy \\ dr.ma.el.shhawy@gmail.com
}

Received for publication February 23, 2021; Accepted April 13, 2021; Published online April 13, 2021.

Copyright 2020 The Authors published by Al-Azhar University, Faculty of Medicine, Cairo, Egypt. All rights reserved. This an openaccess article distributed under the legal terms, where it is permissible to download and share the work provided it is properly cited. The work cannot be changed in any way or used commercially.

doi: 10.21608/aimj.2021.58825.1408

${ }^{1}$ Department of Pediatric surgery, Nasser institute for research and treatment, Cairo

${ }^{2}$ Department of Pediatric surgery, Faculty of Medicine, Al-Azhar University, Egypt

\begin{abstract}
Background: Hyperhidrosis can be defined as a condition of excessive sweating beyond the body's needs to maintain its temperature within an adequate range. Treatment for primary palmar and axillary hyperhidrosis and facial blushing depends on sympathetic denervation of the affected area which is usually the region innervated by sympathetic ganglia T2, $\mathrm{T} 3$, and T4. This can be achieved by sectioning of the sympathetic chain using scissors, electric scalpel, ultrasonic scalpel, or clipping of the chain.

Aim of the work: To compare the efficacy between thoracoscopic sympathectomy using metal clips and thoracoscopic sympathectomy using electrocautery as a treatment for primary hyperhidrosis in children to relieve the excessive sweating and improve the patient`s quality of life.

Material and Methods: A randomized comparative study on 40 patients suffering from primary hyperhidrosis These patients were allocated randomly into 2 groups. Group (A) was treated by thoracoscopic sympathectomy using clipping technique and group (B) was treated by thoracoscopic sympathectomy using electrocautery technique. Data was tabled and analyzed.

Result: A total of 40 patients were enrolled. Success rate among the clipping group was (19/20) 95\% and among the electrocautery group was $(17 / 20) 85 \%$, p value was 0.292 , compensatory sweating was developed in 11 patients of the clipping group (55\%) most of them was of mild to moderate degree and in 11 patients of the electrocautery group (55\%) most of them was of mild to moderate degree, p value 0.367 . We reversed the procedure in one of our clipping technique patients and showed improvement of the degree of the compensatory hyperhidrosis.

Conclusion: Thoracoscopic sympathectomy has been shown to be the most effective treatment for primary hyperhidrosis. Our results showed that clipping technique was as effective as electrocautery technique. Unfortunately, not only the success rates were equal but also the rates of compensatory sweating were found to be similar. The clipping technique offered the advantage of potential reversibility of the procedure in case of severe compensatory hyperhidrosis developed.
\end{abstract}

Keywords: Thoracoscopic; Sympathectomy; clipping; Hyperhidrosis.

Disclosure: The authors have no financial interest to declare in relation to the content of this article. The Article Processing Charge was paid for by the authors.

Authorship: All authors have a substantial contribution to the article.

\section{INTRODUCTION}

Hyperhidrosis is a pathological condition in which sweating occur beyond the body's needs to maintain its temperature within normal range. It appears that primary hyperhidrosis related to a dysfunction of the thermoregulation capacity of the autonomic nervous system. Treatment for primary hyperhidrosis consists of sympathetic denervation of the affected area which is most likely to be the region innervated by sympathetic ganglia R2, R3, and R4. ${ }^{1}$ Thoracoscopic sympathectomy is the gold standard and a well tolerated procedure and its complications are rare.
The most common and the worst secondary effect of sympathectomy is compensatory sweating mainly involving back, abdomen, and lower limbs. ${ }^{2}$

The clipping technique has multiple advantages as It can be performed safely and efficiently. Although clipping is as effective as any other sympathectomy method, but it is potentially reversible if the patient develops severe compensatory sweating. If severe compensatory sweating occurs, clip removal is an option. As clipping is a minimal procedure with limited dissection, the clip(s) on the thoracic sympathetic chain can be easily identified, accessed, and removed at another session. ${ }^{3}$ 
In this prospective comparative study, we report our own results of endoscopic thoracic sympathectomy, comparing clipping and cautery techniques. Furthermore, we performed a thorough review of the up-to-date international literature.

\section{MATERIAL AND METHODS}

After approval from ethical review committee, a randomized comparative prospective study was conducted in pediatric surgery departments in $\mathrm{Al}$ Hussain university hospital, Said Galal university hospital and Nasser institute hospital for research and treatment from March 2018 to December 2020. The study included 40 patients diagnosed with primary hyperhidrosis either palmer and/or axillary. The main diagnostic criteria were visible exaggerated sweat, lasting for at least six months, with no apparent cause, excluding causes of secondary hyperhidrosis (e.g. hyperthyroidism, DM., TB.) and with at least 2 of the following, Bilateral and symmetrical sweat, Frequency of at least one episode per week, Impairment in daily activities, Age of the onset less than 16 years old, Presence of family history, Absence of sweat during sleep. ${ }^{4}$

These patients were allocated randomly into two groups, group A was treated by thoracoscopic sympathectomy using clipping technique and group B: was treated by thoracoscopic sympathectomy using electrocautery technique.

Cases included in this study were selected according to following inclusion criteria, both sexes were included, All ages under 16 and patients suffering from primary hyperhidrosis (palmer and/or axillary) and the exclusion criteria were patients suffering from secondary hyperhidrosism and recurrent 1ry hyperhidrosis after thoracoscopic sympathectomy

Preoperative preparations included thorough history taking, general and local examination, and chest Xray, and if any abnormalities noticed in the chest $\mathrm{X}$ ray, Chest CT scan was ordered.

Preoperative investigations were performed for all patients including; full blood count, random blood sugar, coagulation profile, liver enzymes and serum creatinine . The eligible patients were admitted to the hospital 1 day before the operation day.

The patient`s quality of life (QOL) was assessed before the surgery using Campos Questionnaire (Campos) which developed specifically to evaluate the results of sympathectomy by thoracoscopy as a treatment of palmar hyperhidrosis.

Before the procedure, informed written consent was taken from all patients, patients' parents or guardians, explaining the nature of the disease, risks and complications of the procedures.

Patients were randomly allocated in 2 groups, Group A was treated using clipping technique and group B was treated using electrocautery technique.

General anesthesia was used using normal endotracheal tube with an experienced anesthesiologist who used one lung ventilation anaesthesia to control patient's O2 enriched ventilation in a low-volume/high-frequency technique, alternating brief periods of apnea.

The patient was placed in semi-fowler position (Fig. 1 ), which is dorsal decubitus position with abducted and fixed arms at 90 degrees. The trunk was elevated in 30-40 degrees.

This elevation helped to displace the lungs downwards. a slight bed elevation at the knee level was useful to safely place the patients and avoided them to slip down during the procedure. The procedure was started by approaching the patient's dominant side first, so that if any unexpected intraoperative complication happens and the surgery has to be aborted, there will be a chance that at least the dominant side was treated.

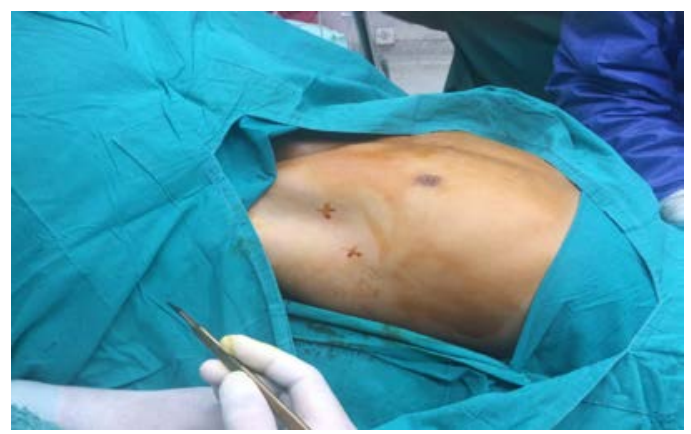

Fig. 1: Semi-fowler position.

If there was a preoperative anticipation of difficulties at one side, we started the procedure by the supposedly easier side, in order to ensure that at least one side was treated, even if problems occur when approaching the contralateral difficult side.

To access the pleural cavity we used two-port video thoracoscopy technique using two $5 \mathrm{~mm}$ ports.

The camera port was placed laterally at the fourth or the fifth intercostal space (depending on the age of the patient), at the middle axillary line.

The second port was placed laterally at the third intercostal space just posterior to the anterior axillary fold formed by the pectoralis major muscle, that approach provided excellent aesthetic results (Fig. 2).

CO2 insufflation was applied at maximum $7 \mathrm{mmHg}$ and the overlying parietal pleura was incised over the sympathetic chain.

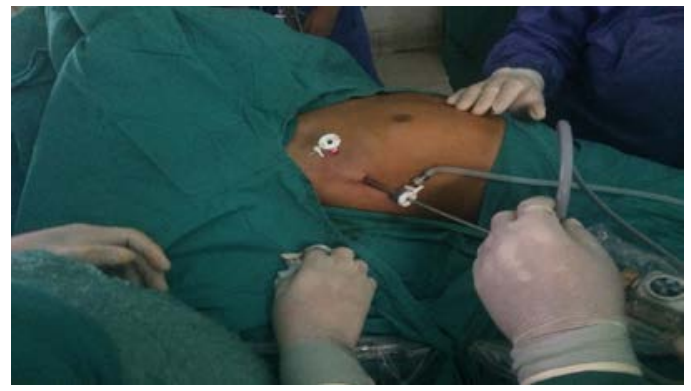

Fig. 2: Ports site.

Patients in group A, Interruption of the sympathetic chain without transection was done using metallic clips (Titanium, Endo Clip $^{\mathrm{TM}}$, COVIDIEN) applied 
across the trunk, after dissection and isolation of the sympathetic chain away from the parietal pleura and the inner thoracic wall (Fig. 3,4).

Patients in group B, Interruption of the sympathetic chain with transection were done using an electrocautery hook (Fig. 5).

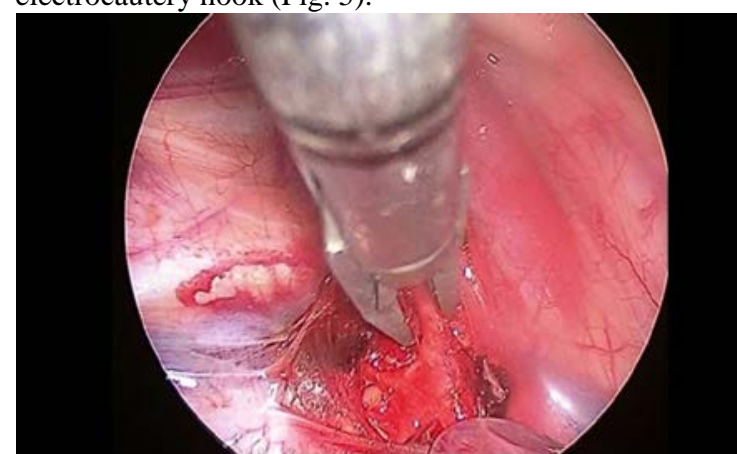

Fig. 3: The sympathetic chain dissected, isolated and ready to be clipped.

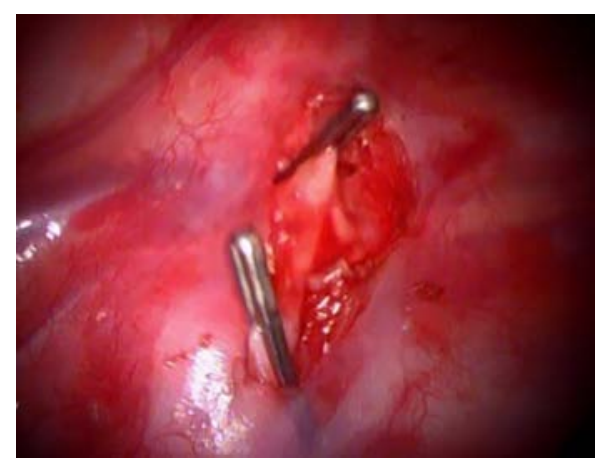

Fig. 4: The sympathetic chain clipped.
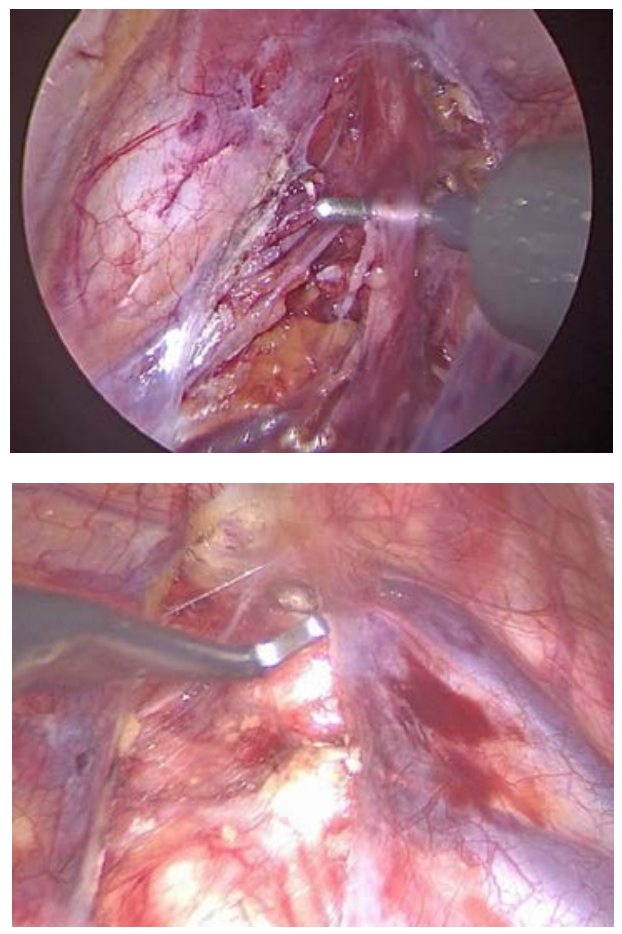

Fig. 5: The sympathetic chain dissected, isolated and cauterized.
Pediatric surgery

Tiny collateral fibers arising from the sympathetic trunk can be present called "Kuntz nerves" which can be responsible for persisting hyperhidrosis after thoracoscopic sympathectomy. In order to avoid that, we extended the chain interruption for about $2 \mathrm{~cm}$ laterally over the inner face of the ribs, so these small nerves have been properly transected.

Local hemostasis was done and, if necessary, testing the lungs for air leaks. Once active bleeding and air leaks were ruled out, the surgically induced pneumothorax is totally evacuated under direct vision without chest tube and wounds were closed (Fig. 6).

Postoperative analgesic regimen included ordinary analgesics and non-steroid anti-inflammatory agents and postoperative routine chest X-ray was obtained in all patients after the surgery to rule out significant pneumothorax and to assess the level of the clips in case of clipping group (Fig. 7).

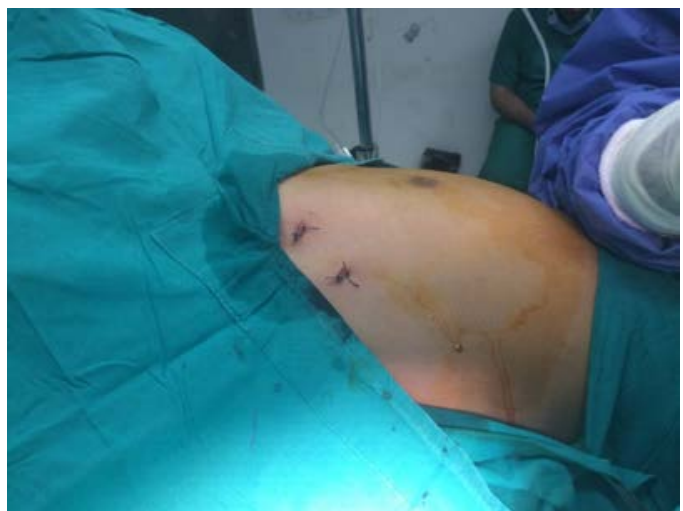

Fig. 6: Ports site after wound closure.

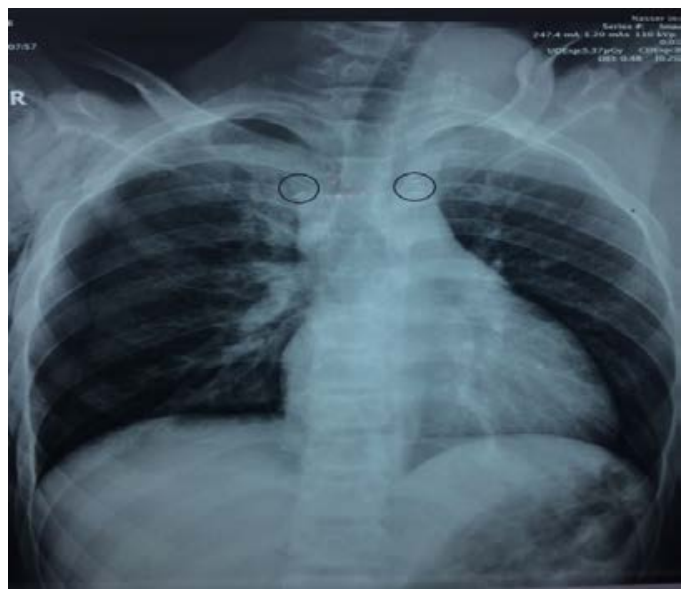

Fig. 7: Chest $\mathrm{X}$-ray showing the site of the clips at the 3rd intercostal space.

The patient`s quality of life (QOL) was assessed at 2 intervals, at one week and at one month, after the surgery using Campos Questionnaire.

Data were collected, revised, coded and entered to the Statistical Package for Social Science (SPSS) version 23 and the following were done, Qualitative data were presented as numbers and percentages, while quantitative data were presented as mean, standard deviations and ranges. The comparison 
between two groups with qualitative data was done by using Chi-square test and the comparison between two independent groups with quantitative data and parametric distribution was done by using Independent t-test.

The confidence interval was set to $95 \%$ and the margin of error accepted was set to $5 \%$. So, the pvalue was considered significant as the following, $\mathrm{P}$ $>0.05$ : Non-significant (NS), $\mathrm{P}<0.05$ : significant (S), $\mathrm{P}<0.01$ : highly significant (HS).

\section{RESULTS}

In group A: The age of patients included ranged from 6 to 16 years (mean age was $12.05 \pm 3.50$ years). Of these patients 12 were females and 8 were males, Their BMI was ranged from 13.8 to 27.6 (mean BMI was $21.02 \pm 4.52$ ).

In group B: The age of patients included ranged from 7 to 16 years (mean age was $12.45 \pm 2.98$ years). Of these patients 12 were females and 8 were males, Their BMI was ranged from 13.9 to 25.9 (mean BMI was $20.58 \pm 3.65$ ) (Table. 1).

In our study $100 \%$ of the patients was presented by bilateral symmetrical sweat with more than one episode per day and caused them impairment in their daily activity. The age of onset In group A ranged from 1 - 10 years with mean age of $4.6 \pm 2.76$ years, While in group B, The age of onset ranged from 1 - 9 years with mean age of $4.65 \pm 2.66$ years and that difference was statistically insignificant $(P=0.954)$

Family history was positive in 10 patients (25\%) 3 from group A and 7 from group $\mathrm{B}$ and the difference was statistically insignificant $(\mathrm{P}=0.144)$.

\begin{tabular}{|c|c|c|c|c|c|c|}
\hline & $\begin{array}{l}\text { Clipping } \\
\text { (group } \\
\text { A) }\end{array}$ & $\begin{array}{l}\text { Cautery } \\
\text { (group B) }\end{array}$ & \multirow{2}{*}{ 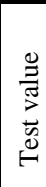 } & \multirow{2}{*}{ 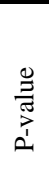 } & \multirow{2}{*}{ 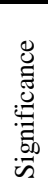 } \\
\hline & & No. $=20$ & No. $=20$ & & & \\
\hline$\stackrel{\text { 品 }}{<}$ & $\begin{array}{l}\text { Mean } \pm \\
\text { SD } \\
\text { Range }\end{array}$ & $\begin{array}{c}12.45 \pm \\
2.98 \\
\\
7-16\end{array}$ & $\begin{array}{c}12.05 \pm \\
3.50 \\
6-16\end{array}$ & 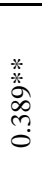 & $\begin{array}{l}\text { ठి } \\
\text { : }\end{array}$ & NS \\
\hline ڤึ & $\begin{array}{l}\text { Fema- } \\
\text { les } \\
\text { Males }\end{array}$ & $\begin{array}{c}12 \\
(60.0 \%) \\
\quad 8 \\
(40.0 \%)\end{array}$ & $\begin{array}{c}12 \\
(60.0 \%) \\
\quad 8 \\
(40.0 \%)\end{array}$ & $\begin{array}{l}\stackrel{*}{\circ} \\
\stackrel{8}{8} \\
\stackrel{0}{0}\end{array}$ & هُ & NS \\
\hline$\sum_{\infty}$ & $\begin{array}{l}\text { Mean } \pm \\
\text { SD } \\
\text { Range }\end{array}$ & $\begin{array}{c}20.58 \pm \\
3.65 \\
\\
13.9- \\
25.9\end{array}$ & $\begin{array}{c}21.02 \pm \\
4.52 \\
\\
13.8- \\
27.6\end{array}$ & 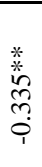 & $\underset{\stackrel{9}{\hat{~}}}{0}$ & NS \\
\hline
\end{tabular}

*: Chi-square test; **: Independent t-test

Table 1: Comparison between clipping and cautery techniques regarding demographic data.

The collective complications rate of our study was $15 \%$ in group A and $25 \%$ in group B and the difference between the two groups was statistically insignificant $(\mathrm{P}=0.429)$. Only two patients showed recurrence of the symptoms one from the cautery group showed recurrence of the symptoms at the axillary region which was managed by redo sympathectomy at R4 with complete resolution of the symptoms postoperative, the other patient was from the clipping group showed recurrence of the symptoms at the palmer region on the right side which was managed by redo sympathectomy R3 with complete resolution of the symptoms postoperative. Both patients was managed using their original technique (Table. 3).

\begin{tabular}{|c|c|c|c|c|c|}
\hline & $\begin{array}{l}\text { Clipping } \\
\text { (group } \\
\text { A) }\end{array}$ & $\begin{array}{l}\text { Cautery } \\
\text { (group } \\
\text { B) } \\
\end{array}$ & \multirow[t]{2}{*}{$\begin{array}{l}\text { Test } \\
\text { value }\end{array}$} & \multirow[t]{2}{*}{$\begin{array}{l}\text { P- } \\
\text { value }\end{array}$} & \multirow[t]{2}{*}{ Sig. } \\
\hline & No. $=20$ & No. $=20$ & & & \\
\hline $\begin{array}{l}\text { Postoperative } \\
\text { complication }\end{array}$ & $3(15.0 \%)$ & $5(25.0 \%)$ & $0.625 *$ & 0.429 & NS \\
\hline Recurrence & $1(5.0 \%)$ & $1(5.0 \%)$ & $0.000 *$ & 1.000 & NS \\
\hline
\end{tabular}

*: Chi-square test;**: Independent t-test

Table 2: Comparison between clipping (group A) and cautery (group B) techniques regarding postoperative Stay and postoperative complications.

The compensatory sweating was considered a side effect of the procedure rather than a complication, In our study $70 \%$ of group A and $75 \%$ of group B developed compensatory sweating and it was ranging from mild to severe degree, yet only $15 \%$ from group A and $20 \%$ from group B was classified as severe degree and the difference between the 2 groups was statistically insignificant $(\mathrm{P}=0.367)$ (Table. 3$)$.

\begin{tabular}{|c|c|c|c|c|c|}
\hline \multirow{2}{*}{$\begin{array}{l}\text { Degree of } \\
\text { compensatory } \\
\text { sweating }\end{array}$} & $\begin{array}{l}\text { Clipping } \\
\text { (group A) }\end{array}$ & $\begin{array}{l}\text { Cautery } \\
\text { (group B) }\end{array}$ & \multirow{2}{*}{ 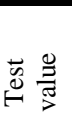 } & \multirow{2}{*}{ 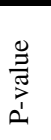 } & \multirow{2}{*}{$\stackrel{\infty}{\infty}$} \\
\hline & No. $=20$ & No. $=20$ & & & \\
\hline Negative & 6 (30.0\%) & $\begin{array}{c}5 \\
(25.0 \%)\end{array}$ & \multirow{4}{*}{ 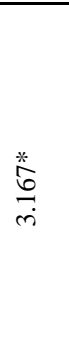 } & \multirow{4}{*}{$\begin{array}{l}\hat{0} \\
\text { mె. } \\
0\end{array}$} & \\
\hline Mild & 3 (15.0\%) & $\begin{array}{c}7 \\
(35.0 \%)\end{array}$ & & & \\
\hline Moderate & 8 (40.0\%) & $\begin{array}{c}4 \\
(20.0 \%)\end{array}$ & & & Z \\
\hline Severe & 3 (15.0\%) & $\begin{array}{c}4 \\
(20.0 \%)\end{array}$ & & & \\
\hline
\end{tabular}

*: Chi-square test.

Table 3: Comparison between clipping (group A) and cautery (group B) techniques regarding degree of compensatory sweating post operative.

The success rate in our study of the clipping group and cautery group was $95 \%$ and $85 \%$ respectively and there was no statistically significant difference $(\mathrm{P}$ $=0.292)$ (Table. 4). 


\begin{tabular}{|c|c|c|c|c|c|c|}
\hline & $\begin{array}{l}\text { Clippin } \\
\text { g } \\
\text { (group } \\
\text { A) }\end{array}$ & $\begin{array}{l}\text { Cautery } \\
\text { (group } \\
\text { B) }\end{array}$ & \multirow{2}{*}{ 俈 } & \multirow{2}{*}{ 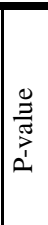 } & \multirow{2}{*}{$\stackrel{\infty}{\infty}$} \\
\hline & & $\begin{array}{l}\text { No. }= \\
20\end{array}$ & $\begin{array}{l}\text { No. }= \\
20\end{array}$ & & & \\
\hline \multirow{2}{*}{ 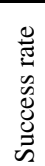 } & No & $\begin{array}{c}1 \\
50 \%\end{array}$ & $\begin{array}{c}3 \\
3\end{array}$ & \multirow{2}{*}{$\exists$} & \multirow[b]{2}{*}{ సิ } & \multirow[b]{2}{*}{ z } \\
\hline & Yes & $\begin{array}{c}19 \\
(95.0 \%)\end{array}$ & $\begin{array}{c}17 \\
(85.0 \%)\end{array}$ & & & \\
\hline
\end{tabular}

*: Chi-square test.

Table 4: Comparison between clipping (group A) and cautery (group B) techniques regarding degree of patient`s satisfaction and Success rate.

\section{DISCUSSION}

Primary hyperhidrosis is not just a physical disease as it has major psychological effect and has a marked impact on the patient's quality of life. In our study, once the diagnosis is confirmed and the surgical indication is well established, we propose ETS (endoscopic thoracic sympathectomy) to patients who are old enough to precise to what extent hyperhidrosis is actually something that negatively impacts their quality of life.

In the study of Bell D et al, The probability and severity of compensatory sweating was noted to vary with age and the variation was significant $(\mathrm{P}=$ 0.0006). The probability of experiencing no compensatory sweating was highest at young ages and decreased with advancing age. The probability of severe sweating was lowest at a young age, so it worth mentioning that there is evidence that a younger age might be a predictor of good outcome after sympathectomy, regarding the risk of compensatory hyperhidrosis, personal satisfaction and cure of symptoms. ${ }^{5}$

The complications rate in our study was $15 \%$ in group A and $25 \%$ in group B. The same rate of complication was observed in the study of Findikcioglu A et al., which showed 3 cases of pneumothorax in each of the clipping and cautery groups with total collective percentage of $10 \%$, yet the rate of recurrence was a little higher as it occurred in 11 patients (39.3\%) in the cautery group and 4 patients $(12.5 \%)$ in the clipping group with collective percentage of $25 \%$. $^{3}$

On the contrary, the study of Kocher GJ et al. showed only one case of pneumothorax due to air leakage which resolved spontaneously after chest tube insertion. $^{2}$

In the study of Musa AF et al., one patient developed a rare complication in the form of bradycardia. ${ }^{6}$

In our study $70 \%$ of group A and $75 \%$ of group B developed compensatory sweating and it was ranging from mild to severe degree. The same results was found in the study of Findikcioglu A et al., as $71.4 \%$ (17.9 severe degree) from the cautery group and $71.9 \%$ (18.8 severe degree) from the clipping group developed compensatory sweating and the difference between the 2 groups was statistically insignificant $(\mathrm{P}=0.8){ }^{3}$

In another recent study conducted by Huang $\mathrm{L}$ et al., compensatory sweating was developed in $45.5 \%$ of the total patients included in the study with about $12.5 \%$ of a severe degree. ${ }^{7}$

In a meta-analysis by Du X et al., the difference of severe compensatory hyperhidrosis between sympathectomy using cautery and clipping is not significant (OR: 1.49, 95\% CI: 0.93-2.39, $\mathrm{P}=0.10$ ), Yet clipping has a significant lower incidence of compensatory hyperhidrosis (OR: 1.58, 95\% CI: 1.04-2.38, $\mathrm{P}=0.03){ }^{8}$

the success rate of the clipping group and cautery group was $95 \%$ and $85 \%$ respectively In support to our results Findikcioglu A et al., had similar success rate as their results showed that, the success rate was $86 \%$ of the clipping group and $83 \%$ of the cautery group and that difference was statistically insignificant $(\mathrm{P}=0.3)^{3}{ }^{3}$

On the other hand the study of Kocher GJ et al., showed that the success rate in the patient suffering from palmer hyperhidrosis was higher in the cautery group with $100 \%$ success rate in comparison with the clipping group which showed success rate of only $96 \% \mathrm{~m}$ yet the difference was statistically insignificant $(\mathrm{P}=1)^{2}{ }^{2}$

\section{CONCLUSION}

Our study found that there is no statistically significant difference between the clipping and the cautery technique regarding operative time, rate of complication, compensatory hyperhidrosis, patient satisfaction and success rate, Yet the clipping technique has the potential reversibility in case of severe compensatory hyperhidrosis developed.

\section{REFERENCES}

1. Vannucci $F$ and Araújo JA. Thoracic sympathectomy for hyperhidrosis: from surgical indications to clinical results. $J$ Thorac Dis. 2017;9 (Suppl 3):S178-92.

2. Kocher GJ, Taha A, Ahler M, et al. Is clipping the preferable technique to perform sympathicotomy? A retrospective study and review of the literature. Langenbecks Arch Surg. 2015; 400(1):107-12

3. Findikcioglu A, Kilic D and Hatipoglu A. Is clipping superior to cauterization in the treatment of palmar hyperhidrosis? Thorac Cardiovasc Surg. 2014;62:445-9.

4. Romero FR, Haddad GR, Miot HA, et al. Palmar hyperhidrosis: clinical, pathophysiological, diagnostic and therapeutic aspects. An Bras Dermatol. 2016;91(6):716-25. . - 
5. Bell D, Jedynak J and Bell R. Predictors of outcome following endoscopic thoracic sympathectomy. ANZ J Surg. 2014;84:68-72.

6. Musa AF, Gandhi VP, Dillon J, et al. A retrospective review on minimally invasive technique via endoscopic thoracic sympathectomy (ETS) in the treatment of severe primary hyperhidrosis: Experiences from the National Heart Institute, Malaysia [version 1; peer review: 2 approved]. F1000Research. 2018; 7: 670.

https://doi.org/10.12688/f1000research.14777.1
7. Huang L, Jiang H, Wei D, et al. A comparative study of thoracoscopic sympathectomy for the treatment of hand sweating. $J$ Thorac Dis. 2019;11(8):3336-3340.

$\underline{\text { doi:10.21037/jtd.2019.08.18 }}$

8. Du X, Zhu X, Wang T, et al. Compensatory hyperhidrosis after different surgeries at the same sympathetic levels: a meta-analysis. Ann Transl Med. 2018; 6(11): 203.

doi:10.21037/atm.2018.05.24 